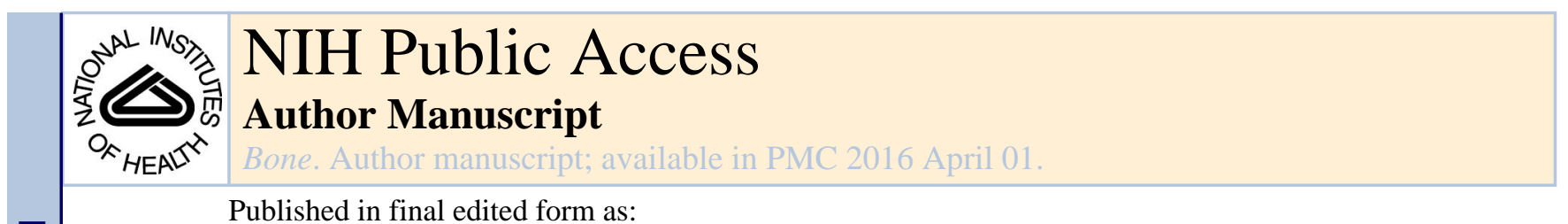

Published in final edited form as:

Bone. 2015 April ; 0: 60-68. doi:10.1016/j.bone.2014.12.012.

\title{
Prevention of Glucocorticoid Induced-Apoptosis of Osteoblasts and Osteocytes by Protecting against Endoplasmic Reticulum (ER) Stress in vitro and in vivo in Female Mice
}

\author{
Amy Y. Sato ${ }^{1}$, Xiaolin Tu ${ }^{1}$, Kevin A. McAndrews ${ }^{1,3}$, Lilian I. Plotkin ${ }^{1,3}$, and Teresita \\ Bellido ${ }^{1,2,3}$ \\ ${ }^{1}$ Department of Anatomy \& Cell Biology; Indianapolis, Indiana, USA \\ 2Department of Medicine, Division of Endocrinology, Indiana University School of Medicine; \\ Indianapolis, Indiana, USA \\ ${ }^{3}$ Roudebush Veterans Administration Medical Center, Indianapolis, Indiana, USA
}

\begin{abstract}
Endoplasmic reticulum (ER) stress is associated with increased reactive oxygen species (ROS), results from accumulation of misfolded/unfolded proteins, and can trigger apoptosis. ER stress is alleviated by phosphorylation of eukaryotic translation initiation factor $2 a$ (eIF2a), which inhibits protein translation allowing the ER to recover, thus promoting cell viability. We investigated whether osteoblastic cell apoptosis induced by glucocorticoids (GC) is due to induction of ROS/ER stress and whether inhibition of eIF2a dephosphorylation promotes survival opposing the deleterious effects of GC in vitro and in vivo. Apoptosis of osteocytic MLO-Y4 and osteoblastic OB-6 cells induced by dexamethasone was abolished by ROS inhibitors. Like GC, the ER stress inducing agents brefeldin A and tunicamycin induced osteoblastic cell apoptosis. Salubrinal or guanabenz, specific inhibitors of eIF2a dephosphorylation, blocked apoptosis induced by either GC or ER stress inducers. Moreover, GC markedly decreased mineralization in OB-6 cells or primary osteoblasts; and salubrinal or guanabenz increased mineralization and prevented the inhibitory effect of GC. Furthermore, salubrinal (1 mg/kg/day) abolished osteoblast and osteocyte apoptosis in cancellous and cortical bone and partially prevented the loss of BMD at all sites and the decreased vertebral cancellous bone formation induced by treatment with prednisolone for 28 days $(1.4 \mathrm{mg} / \mathrm{kg} / \mathrm{day})$. We conclude that part of the pro-apoptotic actions of GC on osteoblastic cells are mediated through ER stress, and that inhibition of eIF2a dephosphorylation protects from GC-induced apoptosis of osteoblasts and osteocytes in vitro and in vivo and from the deleterious effects of GC on the skeleton.
\end{abstract}

(C) 2014 Elsevier Inc. All rights reserved.

Corresponding author and person to whom reprint requests should be addressed: Teresita Bellido, PhD, Department of Anatomy \& Cell Biology, and Department of Internal Medicine, Endocrinology; Indiana University School of Medicine, 635 Barnhill Drive, MS5045A; Indianapolis, Indiana 46202, USA, Phone: 317-274-7410, FAX: 317-278-2040, tbellido@iupui.edu.

Publisher's Disclaimer: This is a PDF file of an unedited manuscript that has been accepted for publication. As a service to our customers we are providing this early version of the manuscript. The manuscript will undergo copyediting, typesetting, and review of the resulting proof before it is published in its final citable form. Please note that during the production process errors may be discovered which could affect the content, and all legal disclaimers that apply to the journal pertain.

Disclosure Statement: The authors have nothing to disclose. 


\section{Key terms}

Glucocorticoid-induced osteoporosis; osteoblasts; osteocytes; endoplasmic reticulum stress

\section{INTRODUCTION}

Excess of glucocorticoids (GC), either endogenous as in aging or due to glucocorticoid administration as immunosuppressants, leads to loss of bone [1]. Chronic GC therapy is prescribed for a multitude of medical conditions including autoimmune diseases such as rheumatoid arthritis, organ transplants, asthma, as a component of cancer chemotherapies, and a variety of inflammatory afflictions [2,3]. Patients with chronic GC exposure exhibit a consistent reduced bone formation rate and histomorphometric features of increased bone resorption $[1,4,5]$. Studies with experimental animals in which GC action is blocked in osteoclasts or in osteoblasts/osteocytes, support the notion that GC-induced bone loss occurs in two phases: an early bone loss caused by osteoclast-driven bone resorption, followed by a steady decline in both bone formation and bone resorption [6-8]. Between 30 to 50\% of patients experience at least one bone fracture, with the consequent morbidity and mortality. Approximately $25 \%$ of patients also develop osteonecrosis due to accumulation of apoptotic osteocytes, which increases the risk of femoral head collapse [9]. Thus, understanding the mechanisms of GC action on bone cells and designing therapeutic strategies that prevent the deleterious effects of these drugs is imperative.

Increased apoptosis of osteoblasts and osteocytes is one of the mechanisms that underlie the reduced bone formation and bone fragility that characterize GC-induced osteoporosis [1]. Apoptosis by GC is due to direct hormonal effects on osteoblasts and osteocytes [10-12] and is abolished by overexpressing in these cells the enzyme that inactivates GC, 11betahydroxysteroid dehydrogenase type 2 [7]. The pro-apoptotic effects of GC are mediated through the classical GC receptor and are triggered by rapid activation of the kinases Pyk2 and JNK [11]. GC-induced JNK phosphorylation lies downstream of increased reactive oxygen species (ROS) generation and subsequent activation of pro-apoptotic signaling in osteoblasts [13]. Phosphorylation of eukaryotic translation initiation factor $2 a$ (eIF2a) by double-stranded RNA-activated protein kinase-like ER kinase (PERK) protects cells from oxidative stress and apoptosis under ER stress conditions [14]. Phosphorylated eIF2a slows global rate of protein translation to provide time for the ER to recover from the excessive protein load, allowing the cell to escape from apoptosis [14, 15]. Earlier findings showed that selective inhibition of eIF2a phosphatases with salubrinal or guanabenz protects from apoptosis induced by ER stress [16, 17]. Salubrinal increases the levels of phosphorylated eIF2a and protects PC12 pheochromocytoma cells from apoptosis induced by the ER stressor tunicamycin, in a dose dependent manner at concentrations varying from $1-100$ $\mu \mathrm{M}$ [16]. Further, guanabenz, another eIF2a phosphatase inhibitor, antagonizes the effect of tunicamycin on several cell types at concentrations up to $50 \mu \mathrm{M}$ [17]. We hypothesized that the pro-apoptotic effect of GC on osteoblasts and osteocytes is at least in part due to induction of ER stress, and we investigated here whether the compounds salubrinal and guanabenz that inhibit eIF2a dephosphorylation will promote osteoblastic cell viability and oppose the deleterious effects of GC in vitro and in vivo. 


\section{MATERIALS AND METHODS}

\section{Cell lines}

Primary osteoblastic cells were isolated from the neonatal calvarial bones of C57BL/6 mice, as previously published [18]. Murine primary osteoblastic cells, bone marrow-derived OB-6 osteoblastic cells, and MLO-Y4 osteocytic cells were cultured as previously described [19, 20].

\section{Quantification of cell detachment, apoptosis, and cell viability}

Cell and nuclear morphology was quantified in MLO-Y4 osteocytic cells stably transfected with green fluorescent protein targeted to the nucleus (nGFP), as published [11]. Briefly, cell detachment was assessed by quantifying the number of cytoplasmic processes per cell. Cells were then categorized into one of two groups: having 3 or less processes or having more than 3 processes; and data is reported as percentage of cells with 3 or less processes. Apoptosis was evaluated by quantifying the percentage of cells with chromatin condensation and nuclear fragmentation in the same cultures. Data is reported as percentage of apoptotic cells.

Cells were treated with the anti-oxidant agents $\mathrm{N}$-acetyl cysteine (NAC, $10 \mathrm{mM}$ ), esbelen $(20 \mu \mathrm{M})$, or catalase $(1250 \mathrm{U} / \mathrm{ml})$, the eIF2a phosphatase inhibitors salubrinal $(1-100 \mu \mathrm{M})$ and guanabenz $(10 \mu \mathrm{M})[16,17]$, the bisphosphonate alendronate $(0.1 \mu \mathrm{M})$, or corresponding vehicle (named control in the figures), for one hour. Subsequently, cells were exposed to the pro-apoptotic agents dexamethasone $(1 \mu \mathrm{M})$, etoposide $(50 \mu \mathrm{M})$, brefeldin $\mathrm{A}(2.7 \mu \mathrm{M})$, or tunicamycin $(2.7 \mu \mathrm{M})$ or corresponding vehicle (named vehicle in the figures), for the indicated times. Cell viability was assessed by trypan blue uptake as previously published $[11,18]$. Cells that excluded the dye were considered alive, and stained cells were considered dead. Data is reported as the percentage of dead cells.

\section{Mineralization assay}

Primary osteoblasts or OB-6 cells were plated at a density of 5,000 cells $/ \mathrm{cm}^{2}$ in growth medium consisting of MEM Alpha medium supplemented with $10 \%$ fetal bovine serum and $1 \%$ penicillin/streptomycin. Once cultures reached confluence, medium was replaced by osteogenic medium containing $50 \mu \mathrm{g} / \mathrm{ml}$ ascorbic acid and $10 \mathrm{mM} \beta$-glycerophosphate together with $1 \mu \mathrm{M}$ dexamethasone or its corresponding vehicle (ethanol), and $10 \mu \mathrm{M}$ salubrinal or guanabenz or the corresponding vehicle (DMSO). Medium was replaced every 2-3 days. Mineralization was visualized using von Kossa phosphate staining [21], Alizarin Red S (Sigma-Aldrich) staining [22], or OsteoImage Mineralization Assay Kit (Lonza). Mineralization was quantified using a microplate reader for Alizarin Red S staining $(405 \mathrm{~nm}$ absorbance) and Lonza staining (492/520nm excitation/emission fluorescence).

\section{In vivo study}

C57B1/6 female mice ( $\mathrm{n}=7-11$ per group) were purchased from Harlan (Indianapolis, IN). After a 2 week acclimation period, four-month-old mice were implanted with 60 day slowrelease pellets delivering placebo, $1.4 \mathrm{mg} / \mathrm{kg} / \mathrm{d}$ (GC1) prednisolone, or $2.1 \mathrm{mg} / \mathrm{kg} / \mathrm{d}(\mathrm{GC} 2)$ prednisolone (Innovative Research of America, Sarasota, FL) while under isoflurane 
anesthesia. For this, a small area between the shoulder blades was shaved and cleaned with $70 \% \mathrm{EtOH}$ prior to incision. Daily subcutaneous injections of salubrinal $(1 \mathrm{mg} / \mathrm{kg} / \mathrm{d}$, Tocris Bioscience, USA) or equal volume of vehicle (propylene glycol, Sigma-Aldrich, named control) began 3 days prior to pellet implantation and continued until experiment termination. An additional group of GC2 implanted mice ( $\mathrm{n}=10)$ received $5.25 \mathrm{mg} / \mathrm{kg} / \mathrm{wk}$ alendronate subcutaneous injections starting 3 days before pellet implantation. Mice were sacrificed 28 days after pellet implantation. Institutional Animal Care and Use Committee at Indiana University School of Medicine approved all animal procedures.

\section{Bone mineral density (BMD) measurements}

BMD was determined in live mice by dual-energy x-ray absorptiometry (DXA) scanning using a PIXImus II densitometer (G.E. Medical Systems, Lunar Division, Madison, WI) [23]. Experimental group assignment was randomized by basal spine BMD determined by DXA scanning performed 5 days prior to pellet implantation. DXA scanning was also performed 28 days after pellet implantation.

\section{Bone histomorphometry and apoptosis}

Distal femora were fixed in $10 \%$ neutral buffered formalin. After 48 hours in fixative, samples were transferred to $70 \%$ ethanol, and then embedded undecalcified in methyl methacryate as previously described [12]. Dynamic histomorphometry measurements were performed in 7- $\mu \mathrm{m}$ unstained bone sections under epifluorescence microscopy. For this purpose, $0.6 \%$ calcein and $1.0 \%$ alizarin red solutions were intraperitoneally injected 8 and 3 days prior to sacrifice. Histomorphometric analysis was performed with a computer and digitizer tablet (OsteoMetrics, Decatur, GA) interfaced to a Olympus BX51 fluorescence microscope (Olympus America Inc., Melville, NY) with a drawing tube attachment [24]. Apoptotic cells were detected by transferase-mediated biotin-dUTP nick end-labeling (TUNEL) reaction in undecalcified longitudinal sections of the distal femur, as previously described [12]. Analysis was performed in cancellous and cortical bone, starting $200 \mu \mathrm{m}$ below the growth plate and ending at the mid-diaphysis.

\section{Statistical analysis}

Data is expressed as means \pm standard deviation (SD). Sample differences were assessed using SigmaPlot 12.0 (Systat Software Inc, San Jose, CA), following the appropriate method for each measurement, as indicated in the figure legends. Means were considered significantly different at $\mathrm{p}<0.05$.

\section{RESULTS}

\section{Glucocorticoids induce apoptosis of osteocytic and osteoblastic cells by generating ROS}

The synthetic glucocorticoid dexamethasone induced retraction of osteocytic MLO-Y4 cytoplasmic processes, an early sign of cell detachment that triggers apoptosis (anoikis) [11], as revealed by a reduction in the percentage of cells exhibiting 3 or more cytoplasmic projections (Figure 1A). Dexamethasone also induced apoptosis of MLO-Y4 osteocytic cells, as quantified by evaluating chromatin condensation and nuclear fragmentation (Figure $1 \mathrm{~B}$ and C). Further, dexamethasone increased the percentage of MLO-Y4 and OB-6 
osteoblastic cells exhibiting trypan blue uptake (Figure 1D), another sign of apoptotic cell death induced by GC previously shown to be blocked by inhibiting caspase 3 activity [11, $12,18]$. Pre-treatment with the anti-oxidants NAC, esbelen, or catalase prevented GCinduced apoptosis of either cell type, although for OB-6 cells the inhibitory effect of catalase was incomplete.

\section{Inhibition of elF2a dephosphorylation with salubrinal and guanabenz prevents apoptosis induced by glucocorticoids, etoposide, and ER stressors in osteoblastic cells}

Because ROS induce ER stress, we next investigated whether reduction of ER stress by inhibiting eIF $2 a$ dephosphorylation with salubrinal was able to prevent apoptosis induced by dexamethasone or etoposide, another proapoptotic stimulus that induces apoptosis by inhibiting topoisomerase II and DNA repair. Dexamethasone or etoposide consistently increased MLO-Y4 and OB-6 cell death (Figure 2). Salubrinal did not significantly affect cell viability, except for increasing trypan blue uptake of MLO-Y4 cells at $100 \mu \mathrm{M}$ for 6 hours (Figure 2A). The mechanism behind the decreased viability induced by high concentrations of salubrinal is not known. However, it might be related to a transient increase in the expression of pro-apoptotic protein CHOP as found by Zhang et al in MC3T3 osteoblastic cells [25]. Further, $1-100 \mu \mathrm{M}$ salubrinal prevented cell death induced by dexamethasone in both MLO-Y4 and OB-6 cells (Figure 2A and B). Salubrinal also inhibited the effects of etoposide, but with less efficiency. The $10 \mu \mathrm{M}$ salubrinal concentration was used for subsequent experiments as it consistently prevented dexamethasone-induced apoptosis in MLO-Y4 and OB- 6 cells at both 6 and 24 hour time points. Salubrinal and guanabenz, another inhibitor of eIF2a dephosphorylation, also inhibited apoptosis of OB-6 osteoblastic cells and primary osteoblasts induced by the inducers of ER stress brefeldin A, an inhibitor the ER/Golgi apparatus vesicle transport, and tunicamycin, a protein glycosylation inhibitor [16] (Figure 3A-C). In contrast, alendronate, an agent previously shown to effectively inhibit apoptosis of osteocytic MLO-Y4 cells, osteoblastic OB-6 cells, and primary calvaria derived osteoblasts induced by dexamethasone or etoposide $[12,23,26]$, was unable to prevent the increase in OB-6 cell death induced by the ER stress inducers (Figure 3B).

\section{Salubrinal and guanabenz ameliorate the inhibitory effects of glucocorticoids on matrix mineralization}

We next investigated whether inhibitors of the ER stress alter the effects of GC on matrix mineralization. GC decreased mineral deposition in OB-6 osteoblastic cells cultured under osteogenic conditions, as shown by staining with von Kossa (that detects phosphate) or Alizarin Red S (that detects calcium) (Figure 4A and B), or in primary osteoblasts measured by hydroxyapatite accumulation (Figure 4C). Treatment with salubrinal or guanabenz increased mineralization of OB-6 cells (Figure 5A and B). Further, either compound partially prevented the decreased mineralization induced by GC in OB-6 or primary osteoblasts (Figure 5). Thus, salubrinal increased mineral content in cells treated with GC compared to GC alone after 7 and 10 days of culture (Figure 5A). However, salubrinal treatment could not block GC reductions in mineralization after 14 days of GC exposure, but guanabenz remained effective throughout the two week GC treatment period (Figure 5A-C). 


\section{Salubrinal protects against osteoblast and osteocyte apoptosis in vivo and partially prevents the bone loss induced by glucocorticoids}

We next investigated whether inhibition of eIF2a dephosphorylation promoted bone cell viability also in vivo. Guanabenz appeared to be more potent in opposing the in vitro effects of GC compared to salubrinal. However, guanabenz is also an a2 adrenergic receptor agonist used in the treatment of hypertension [27]. To avoid potential skeletal effects of activating these receptors, we decided to use salubrinal for the in vivo study. C57Bl/6 female mice implanted with pellets containing two different doses of the $\mathrm{GC}$ prednisolone $(\mathrm{GC} 1=$ 1.4 or $\mathrm{GC} 2=2.1 \mathrm{mg} / \mathrm{kg} / \mathrm{d})$ received daily injections of salubrinal $(1 \mathrm{mg} / \mathrm{kg} / \mathrm{d})$. Mice treated with prednisolone exhibited increased apoptosis of osteoblasts in cancellous bone and of osteocytes in both cancellous and cortical bone (Figure 6A). Salubrinal completely blocked GC1-induced apoptosis of both osteoblasts and osteocytes, whereas it only partially prevented the increase in GC2-induced apoptosis of osteoblasts and did not inhibit GC2induced osteocyte apoptosis. On the other hand and consistent with previous findings [23], alendronate effectively prevented GC2-induced apoptosis of both osteoblasts and osteocytes in cancellous bone, although it did not inhibit GC2-induced cortical osteocyte apoptosis. Administration of prednisolone induced a significant decrease in BMD in total body, spine, and femur, at both doses compared to placebo (Figure 6B). Mice implanted with placebo pellets and treated with salubrinal lost significantly less spinal BMD compared to those treated with vehicle. Similarly, mice implanted with GC1 pellets and injected with salubrinal lost significantly less bone compared to mice implanted with GC1 pellets and injected with vehicle. On the other hand, salubrinal did not prevent the loss of bone induced by GC2. In contrast, inhibition of resorption with alendronate not only prevented GC2-induced bone loss, as previously shown [23], but also increased BMD over placebo treated mice. Moreover, $\mathrm{GC} 1$ and $\mathrm{GC} 2$ reduced bone formation rate (BFR) in cancellous bone by a combination of reduction in MS/BS and in MAR (Figure 6C). Salubrinal reversed the decreased BFR induced by GC1 but not GC2. Alendronate reduced further GC2-mediated inhibition of BFR by decreasing both MS/BS and MAR.

\section{DISCUSSION}

Apoptosis of osteoblasts and osteocytes contributes to the reduced bone formation and increased bone fragility in glucocorticoid-induced osteoporosis $[6,7,9]$. Therefore, understanding the mechanisms by which GC induce apoptosis of osteoblastic cells is critical for the development of intervention therapies. Earlier studies demonstrated that apoptosis of osteocytes and osteoblasts is caused by loss of attachment to the extracellular matrix mediated by inside-out signaling downstream of Pyk2/JNK kinases [11] and that GC increase ROS production in bone in vivo and in osteoblastic cells in vitro [13]. We investigated in this study the effect on GC action of salubrinal and guanabenz, eIF2a dephosphorylation inhibitors that block ROS-induced ER stress [16, 17]. These compounds prevented the pro-apoptotic effect of GC on osteoblasts and osteocytes in vitro and the decreased in mineral deposition induced by GC in osteoblastic cell cultures. Further, salubrinal prevented apoptosis of osteoblasts and osteocytes induced by GC in vivo and the concomitant decrease in bone mass and bone formation. 
Consistent with the current study demonstrating inhibition of apoptosis of osteoblasts and osteocytes and improved mineralization by decreasing ER stress, recent evidence demonstrates increased apoptosis of osteoblastic cells and changes in osteoblast differentiation associated with elevated ER stress in vitro with thapsigargin or tunicamycin $[28,29]$. Remarkably, increased ER stress appears to have a time-dependent biphasic effect inducing rapid increase in osteoblast markers Runx 2 and osterix, followed by a reduction in the expression of these transcription factors as well as osteocalcin [28]. Further, ER stressmediated apoptosis of osteoblasts and impaired osteoblast differentiation was also demonstrated in a model of osteogenesis imperfecta [30] and in mice lacking the ERlocalized protein Arl6ip5 in osteoblasts [31]. Consistent with the pro-apoptotic and inhibitory effect of ER stress on osteoblast differentiation, in the current manuscript we show that opposing ER stress by inhibiting eIF2a dephosphorylation prevents osteoblast and osteocyte apoptosis and the decrease in osteoblast function induced by GC in vitro and in vivo. Our findings agree with previous evidence showing that salubrinal increases the number of alkaline phosphatase positive colonies in bone marrow cell cultures [32] and osteocalcin expression in MC3T3-E1 cells [33].

In contrast to the protective effect of salubrinal against the action of low GC dose (GC1), salubrinal was unable to protect the skeleton from the high GC dose (GC2). Similarly, whereas salubrinal or guanabenz effectively prevented the inhibition of mineralization induced by short-term treatment of cultured osteoblasts with GC, only guanabenz was able to reverse the effects of prolonged treatment with GC. The mechanism of the different outcome of guanabenz compared to salubrinal is not known. It remains unclear also the reason for the incomplete inhibition of cortical osteocyte apoptosis by alendronate in this experiment, since in earlier studies alendronate completely prevented apoptosis of osteoblastic cells in both cancellous and cortical bone [23]. A potential explanation is that in the previous study alendronate was administered daily instead of in a weekly 7-day cumulative dose. Nevertheless, these findings suggest that the potency of the pro-apoptotic signals delivered by GC, either due to high dose or prolonged exposure, determines the ability of the protective compound to induced survival and that once a pro-apoptotic threshold is reached, salubrinal is not able to reverse it.

Consistent with the in vitro and in vivo data showing that inhibition of eIF2a dephosphorylation preserves osteoblast viability, treatment with salubrinal reversed the inhibition in BFR induced by low dose of GC mainly by reversing the decrease in MS/BS. These findings together with the demonstration that salubrinal prevents the reduction in mineralization induced by GC in vitro strongly suggest that the preservation of bone mineral density by salubrinal is due to its protective effects on osteoblasts. In contrast, alendronate further reduced BFR in GC treated animals, as expected due to its potent inhibitory effects on osteoclasts and resorption. Salubrinal, like alendronate, has been also shown to inhibit osteoclastogenesis [33] and to protect from ovariectomy-induced bone loss [34]. However, in the setting of GC excess, the main mechanism of salubrinal action appears to be related to osteoblasts. Thus, the bone sparing actions of salubrinal and bisphosphonates on GC excess are mediated by distinct cellular mechanisms. Whereas alendronate inhibits osteoclast 
activity and reduces bone turnover, salubrinal preserves the viability and the bone forming function of osteoblasts.

Protein misfolding is a common feature of several human diseases including neurodegenerative conditions such as Alzheimer's and Parkinson's diseases, as well as type 2 diabetes [35]. Lack of functional PERK, the sensor of the unfolded protein response and a major eIF2a kinase, causes the Wolcott-Rallison syndrome (WRS) in humans, which is characterized by early onset diabetes and aberrant skeletal development [36]. PERK deletion in the mouse prevents the unfolded protein response induced by ER stressors and inhibits phosphorylation of eIF2a [37]. Homozygous PERK null mice are born normal but loose $\beta$ cells rapidly and develop early diabetes [38]. As with WRS patients, PERK knockout mice develop skeletal dysplasia and defective bone mineralization [39]. Osteoblast and osteocyte number, mineral appositional rate MAR, and markers of osteoblasts and osteocytes are decreased in PERK null mice. Osteoblast survival appears not to be affected in vitroalbeit in vivo studies were not shown. Together with the current study in which increased osteoblast and osteocyte apoptosis, decreased bone formation, and decreased bone mass induced by glucocorticoids are partially prevented by salubrinal, these findings suggest that inhibition of eIF2a dephosphorylation is a potential novel target for the treatment of glucocorticoidinduced osteoporosis and other conditions with deficient osteoblast differentiation and bone mineralization.

\section{ACKNOWLEDGEMENTS}

The authors thank Dr. Nicoletta Bivi and Meloney Cregor for technical assistance, Dr. Ziyue Liu for assistance with statistical analysis, and Dr. Hiroki Yokota for advice. This research was supported by the Department of Defense (DM102485), National Institutes of Health (R01AR059357, R01 DK076007, and S10-RR023710 to TB), and the Veterans Administration (Merit Review I01BX002104 to TB).

Funding sources: This research was supported by the Department of Defense (DM102485), NIAMS (R01AR059357), and the Veterans Administration (Merit Review I01BX002104) to TB.

\section{REFERENCES}

1. Weinstein RS. Clinical practice. Glucocorticoid-induced bone disease. N Engl J Med. 2011; 365:6270. [PubMed: 21732837]

2. Jin HO, Seo SK, Woo SH, Kim ES, Lee HC, Yoo DH, An S, Choe TB, Lee SJ, Hong SI, Rhee CH, Kim JI, Park IC. Activating transcription factor 4 and CCAAT/enhancer-binding protein-beta negatively regulate the mammalian target of rapamycin via Redd 1 expression in response to oxidative and endoplasmic reticulum stress. Free Radic Biol Med. 2009; 46:1158-1167. [PubMed: 19439225]

3. Weinstein RS. Glucocorticoid-induced osteoporosis. Rev Endocr Metab Disord. 2001; 2:65-73. [PubMed: 11708295]

4. Dempster DW. Bone histomorphometry in glucocorticoid-induced osteoporosis. J Bone Miner Res. 1989; 4:137-141. [PubMed: 2658477]

5. Reid IR. Glucocorticoid osteoporosis--mechanisms and management. Eur J Endocrinol. 1997; 137:209-217. [PubMed: 9330580]

6. Weinstein RS, Jilka RL, Parfitt AM, Manolagas SC. Inhibition of osteoblastogenesis and promotion of apoptosis of osteoblasts and osteocytes by glucocorticoids: potential mechanisms of their deleterious effects on bone. J Clin Invest. 1998; 102:274-282. [PubMed: 9664068] 
7. O'Brien CA, Jia D, Plotkin LI, Bellido T, Powers CC, Stewart SA, Manolagas SC, Weinstein RS. Glucocorticoids act directly on osteoblasts and osteocytes to induce their apoptosis and reduce bone formation and strength. Endocrinology. 2004; 145:1835-1841. [PubMed: 14691012]

8. Jia D, O'Brien CA, Stewart SA, Manolagas SC, Weinstein RS. Glucocorticoids act directly on osteoclasts to increase their lifespan and reduce bone density. Endocrinology. 2006; 147:55925599. [PubMed: 16935844]

9. Weinstein RS, Nicholas RW, Manolagas SC. Apoptosis of osteocytes in glucocorticoid-induced osteonecrosis of the hip. J Clin Endocrinol Metab. 2000; 85:2907-2912. [PubMed: 10946902]

10. Jilka RL, Weinstein RS, Bellido T, Roberson P, Parfitt AM, Manolagas SC. Increased bone formation by prevention of osteoblast apoptosis with parathyroid hormone. J Clin Invest. 1999; 104:439-446. [PubMed: 10449436]

11. Plotkin LI, Manolagas SC, Bellido T. Glucocorticoids induce osteocyte apoptosis by blocking focal adhesion kinase-mediated survival: evidence for inside-out signaling leading to anoikis. $\mathrm{J}$ Biol Chem. 2007; 282:24120-24130. [PubMed: 17581824]

12. Plotkin LI, Weinstein RS, Parfitt AM, Roberson PK, Manolagas SC, Bellido T. Prevention of osteocyte and osteoblast apoptosis by bisphosphonates and calcitonin. J Clin Invest. 1999; 104:1363-1374. [PubMed: 10562298]

13. Almeida M, Han L, Ambrogini E, Weinstein RS, Manolagas SC. Glucocorticoids and tumor necrosis factor (TNF) alpha increase oxidative stress and suppress WNT signaling in osteoblasts. J Biol Chem. 2011; 286:44326-44335. [PubMed: 22030390]

14. Harding HP, Zhang Y, Zeng H, Novoa I, Lu PD, Calfon M, Sadri N, Yun C, Popko B, Paules R, Stojdl DF, Bell JC, Hettmann T, Leiden JM, Ron D. An integrated stress response regulates amino acid metabolism and resistance to oxidative stress. Mol Cell. 2003; 11:619-633. [PubMed: 12667446]

15. Walter P, Ron D. The unfolded protein response: from stress pathway to homeostatic regulation. Science. 2011; 334:1081-1086. [PubMed: 22116877]

16. Boyce M, Bryant KF, Jousse C, Long K, Harding HP, Scheuner D, Kaufman RJ, Ma D, Coen DM, Ron D, Yuan J. A selective inhibitor of eIF2alpha dephosphorylation protects cells from ER stress. Science. 2005; 307:935-939. [PubMed: 15705855]

17. Tsaytler P, Harding HP, Ron D, Bertolotti A. Selective inhibition of a regulatory subunit of protein phosphatase 1 restores proteostasis. Science. 2011; 332:91-94. [PubMed: 21385720]

18. Bellido T, Ali AA, Plotkin LI, Fu Q, Gubrij I, Roberson PK, Weinstein RS, O'Brien CA, Manolagas SC, Jilka RL. Proteasomal degradation of Runx2 shortens parathyroid hormoneinduced anti-apoptotic signaling in osteoblasts. A putative explanation for why intermittent administration is needed for bone anabolism. J Biol Chem. 2003; 278:50259-50272. [PubMed: 14523023]

19. Lecka-Czernik B, Gubrij I, Moerman EA, Kajkenova O, Lipschitz DA, Manolagas SC, Jilka RL. Inhibition of Osf2/Cbfa1 expression and terminal osteoblast differentiation by PPAR-gamma 2. J Cell Biochem. 1999; 74:357-371. [PubMed: 10412038]

20. Kato Y, Windle JJ, Koop BA, Mundy GR, Bonewald LF. Establishment of an osteocyte-like cell line, MLO-Y4. J Bone Miner Res. 1997; 12:2014-2023. [PubMed: 9421234]

21. Ogawa R, Mizuno H, Watanabe A, Migita M, Shimada T, Hyakusoku H. Osteogenic and chondrogenic differentiation by adipose-derived stem cells harvested from GFP transgenic mice. Biochem Biophys Res Commun. 2004; 313:871-877. [PubMed: 14706623]

22. Tsai SW, Liou HM, Lin CJ, Kuo KL, Hung YS, Weng RC, Hsu FY. MG63 osteoblast-like cells exhibit different behavior when grown on electrospun collagen matrix versus electrospun gelatin matrix. PLoS ONE. 2012; 7:e31200. [PubMed: 22319618]

23. Plotkin LI, Lezcano V, Thostenson J, Weinstein RS, Manolagas SC, Bellido T. Connexin 43 is required for the anti-apoptotic effect of bisphosphonates on osteocytes and osteoblasts in vivo. $\mathrm{J}$ Bone Miner Res. 2008; 23:1712-1721. [PubMed: 18597631]

24. Aguirre JI, Plotkin LI, Stewart SA, Weinstein RS, Parfitt AM, Manolagas SC, Bellido T. Osteocyte apoptosis is induced by weightlessness in mice and precedes osteoclast recruitment and bone loss. J Bone Min Res. 2006; 21:605-615. 
25. Zhang P, Hamamura K, Jiang C, Zhao L, Yokota H. Salubrinal promotes healing of surgical wounds in rat femurs. J Bone Miner Metab. 2012; 30:568-579. [PubMed: 22610062]

26. Bellido T, Plotkin LI. Novel actions of bisphosphonates in bone: Preservation of osteoblast and osteocyte viability. Bone. 2011; 49:50-55. [PubMed: 20727997]

27. Holmes B, Brogden RN, Heel RC, Speight TM, Avery GS. Guanabenz. A review of its pharmacodynamic properties and therapeutic efficacy in hypertension. Drugs. 1983; 26:212-229. [PubMed: 6352237]

28. Hamamura K, Yokota H. Stress to endoplasmic reticulum of mouse osteoblasts induces apoptosis and transcriptional activation for bone remodeling. FEBS Lett. 2007; 581:1769-1774. [PubMed: 17418825]

29. Saito A, Ochiai K, Kondo S, Tsumagari K, Murakami T, Cavener DR, Imaizumi K. Endoplasmic reticulum stress response mediated by the PERK-eIF2(alpha)-ATF4 pathway is involved in osteoblast differentiation induced by BMP2. J Biol Chem. 2011; 286:4809-4818. [PubMed: 21135100]

30. Lisse TS, Thiele F, Fuchs H, Hans W, Przemeck GKH, Abe K, Rathkolb B, Quintanilla-Martinez L, Hoelzwimmer G, Helfrich M, Wolf E, Ralston SH, Habré de Angelis M. ER stress-mediated apoptosis in a new mouse model of osteogenesis imperfecta. PLoS Genet. 2008; 4(2):e7. 4:1-11. [PubMed: 18248096]

31. Wu Y, Yang M, Fan J, Peng Y, Deng L, Ding Y, Yang R, Zhou J, Miao D, Fu Q. Deficiency of osteoblastic Arl6ip5 impaired osteoblast differentiation and enhanced osteoclastogenesis via disturbance of ER calcium homeostasis and induction of ER stress-mediated apoptosis. Cell Death Dis. 2014; 5:e1464. [PubMed: 25321471]

32. Yokota H, Hamamura K, Chen A, Dodge TR, Tanjung N, Abedinpoor A, Zhang P. Effects of salubrinal on development of osteoclasts and osteoblasts from bone marrow-derived cells. BMC Musculoskelet Disord. 2013; 14:197. [PubMed: 23816340]

33. Hamamura K, Tanjung N, Yokota H. Suppression of osteoclastogenesis through phosphorylation of eukaryotic translation initiation factor 2 alpha. J Bone Miner Metab. 2013; 31:618-628. [PubMed: 23536193]

34. Zhang P, Chen A, Dodge TTN, Zheng Y, Fuqua C, Yokota H. Salubrinal Regulates Bone Remodeling and Fat Metabolism in Ovariectomized Mice. Proceedings of the Orthopedic Research Society Annual Meeting. 2013

35. Fullwood MJ, Zhou W, Shenolikar S. Targeting phosphorylation of eukaryotic initiation factor-2alpha to treat human disease. Prog Mol Biol Transl Sci. 2012; 106:75-106. [PubMed: 22340715]

36. Delepine M, Nicolino M, Barrett T, Golamaully M, Lathrop GM, Julier C. EIF2AK3, encoding translation initiation factor 2-alpha kinase 3, is mutated in patients with Wolcott-Rallison syndrome. Nat Genet. 2000; 25:406-409. [PubMed: 10932183]

37. Harding HP, Zhang Y, Bertolotti A, Zeng H, Ron D. Perk is essential for translational regulation and cell survival during the unfolded protein response. Mol Cell. 2000; 5:897-904. [PubMed: 10882126]

38. Harding HP, Zeng H, Zhang Y, Jungries R, Chung P, Plesken H, Sabatini DD, Ron D. Diabetes mellitus and exocrine pancreatic dysfunction in perk-/- mice reveals a role for translational control in secretory cell survival. Mol Cell. 2001; 7:1153-1163. [PubMed: 11430819]

39. Wei J, Sheng X, Feng D, McGrath B, Cavener DR. PERK is essential for neonatal skeletal development to regulate osteoblast proliferation and differentiation. J Cell Physiol. 2008; 217:693-707. [PubMed: 18683826] 


\section{Highlights}

- GC-induced osteoblast/osteocyte apoptosis is mediated by ROS and ER stress.

- $\quad$ IF2a dephosphorylation inhibitors Sal and Gz prevent ER stress induced apoptosis.

- $\mathrm{Sal} / \mathrm{Gz}$ protect from GC-induced apoptosis and impaired mineral deposition in vitro.

- Sal prevented osteoblast/osteocyte apoptosis and loss of BMD induced by GC in vivo.

- eIF2a dephosphorylation is a potential target for treating GC-induced osteoporosis. 

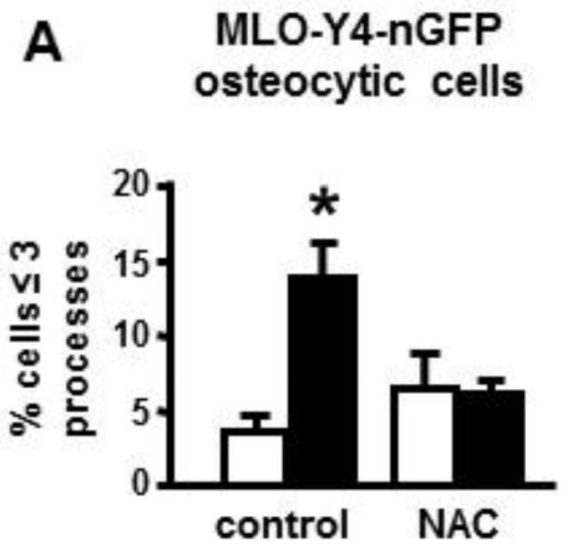
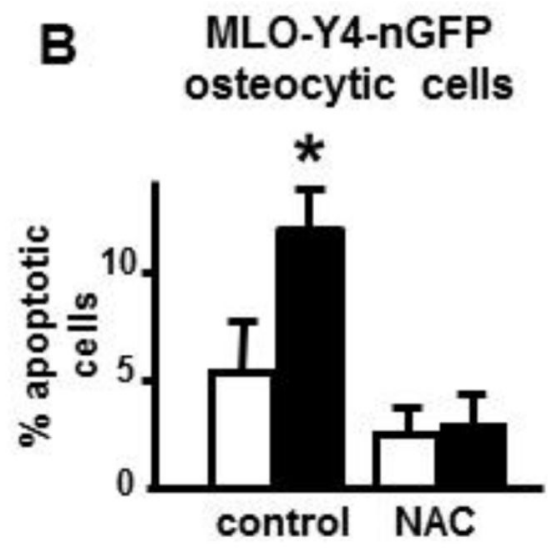

vehicle

dexamethasone

C

dex

$=$
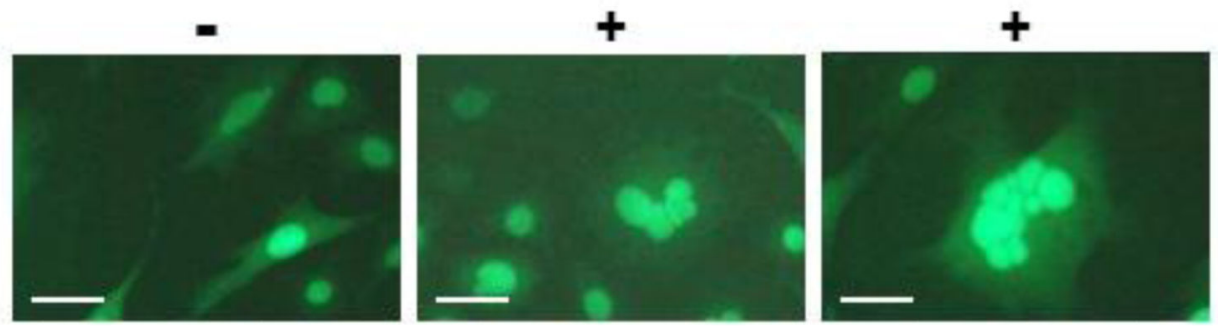

D

MLO-Y4 osteocytic cells

OB-6 osteoblastic cells
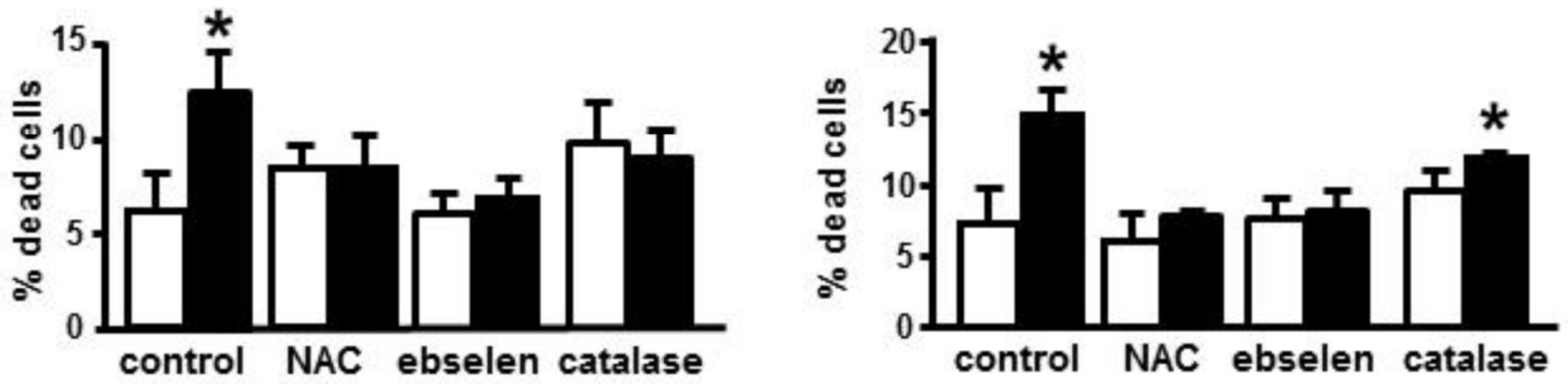

Figure 1. Glucocorticoid-induced apoptosis of osteocytic and osteoblastic cells is prevented by inhibiting ROS generation

(A-D) Cells were exposed to vehicle (ethanol) or dexamethasone for 6 hours. (A)

Quantification of cytoplasmic retraction in stably transfected nGFP MLO-Y4 cells treated with or without NAC for 1 hour prior to addition of dexamethasone. (B) Apoptosis quantification of nGFP-transfected MLO-Y4 cells. (C) Representative images of nGFPexpressing MLO-Y4 osteocytic cells treated with vehicle or dexamethasone showing changes in cell morphology, chromatin condensation, and nuclear fragmentation. Lines correspond to $200 \mu \mathrm{m}$. (D) Quantification of cell death in MLO-Y4 osteocytic or OB-6 osteoblastic cells with or without pretreatment of the indicated anti-oxidant agent, assessed by trypan blue uptake. Bars represent the means $\pm \mathrm{SD}$ of $\mathrm{N}=3$ independent wells/treatment. * $\mathrm{p}<0.05$ vs. the corresponding vehicle-treated cells, by one-way ANOVA. 
A

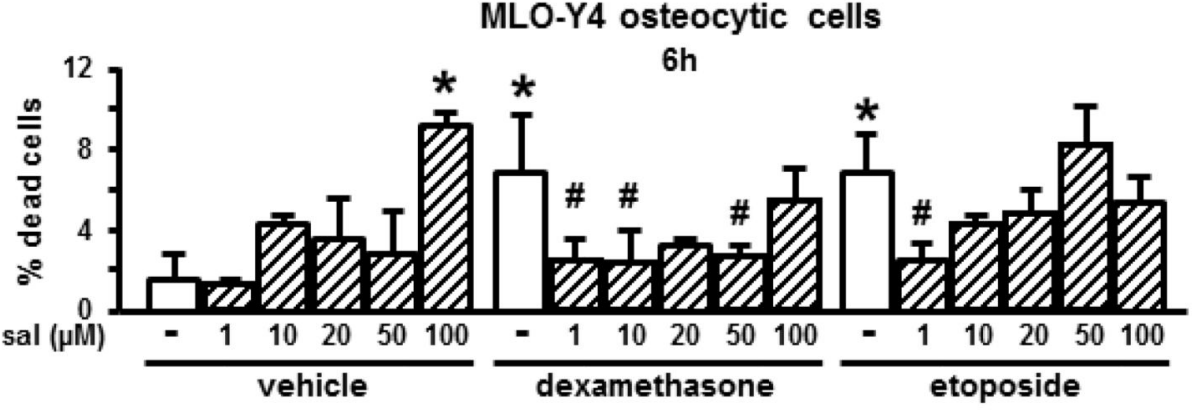

$\mathbf{B}$
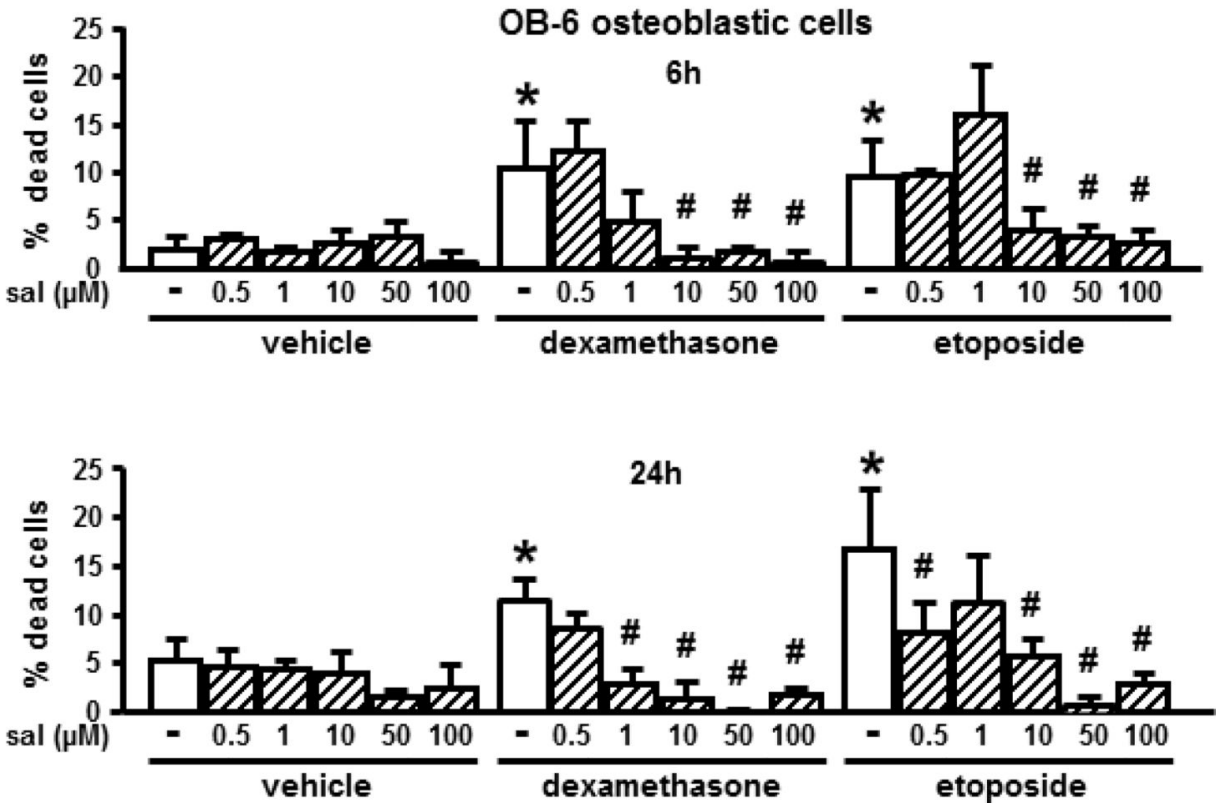

Figure 2. Protection against ER stress with salubrinal prevents dexamethasone and etoposide induced apoptosis of osteocytic MLO-Y4 and osteoblastic OB-6 cells

Cell death quantification in MLO-Y4 osteocytic (A) or OB-6 osteoblastic (B) cells treated with or without salubrinal prior to addition of vehicle, dexamethasone, or etoposide, assessed by trypan blue uptake. Bars represent the means $\pm \mathrm{SD}$ of $\mathrm{N}=3$ samples per treatment. ${ }^{*} \mathrm{p}<0.05$ vs. cells treated with vehicle without salubrinal and \# $\mathrm{p}<0.05$ vs. corresponding apoptotic agent without salubrinal for each time point, by one-way ANOVA. 
A
OB-6 osteoblastic cells

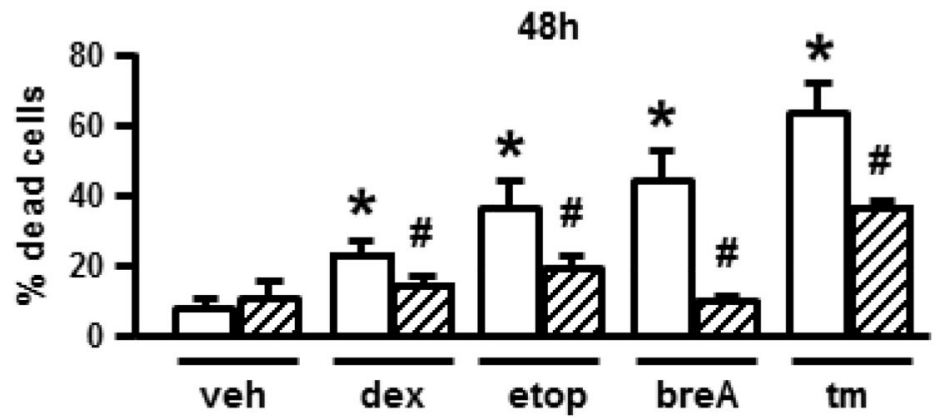

B

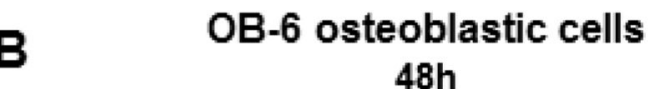

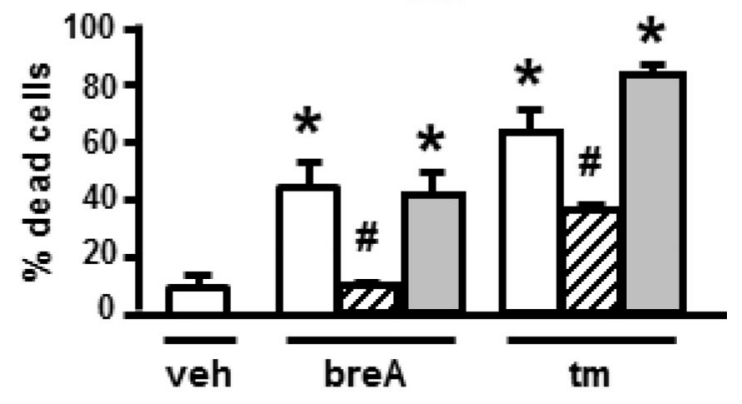

$\square$ control $\square$ salubrinal $\square$ alendronate

C

\section{$6 \mathrm{~h}$}

primary osteoblasts
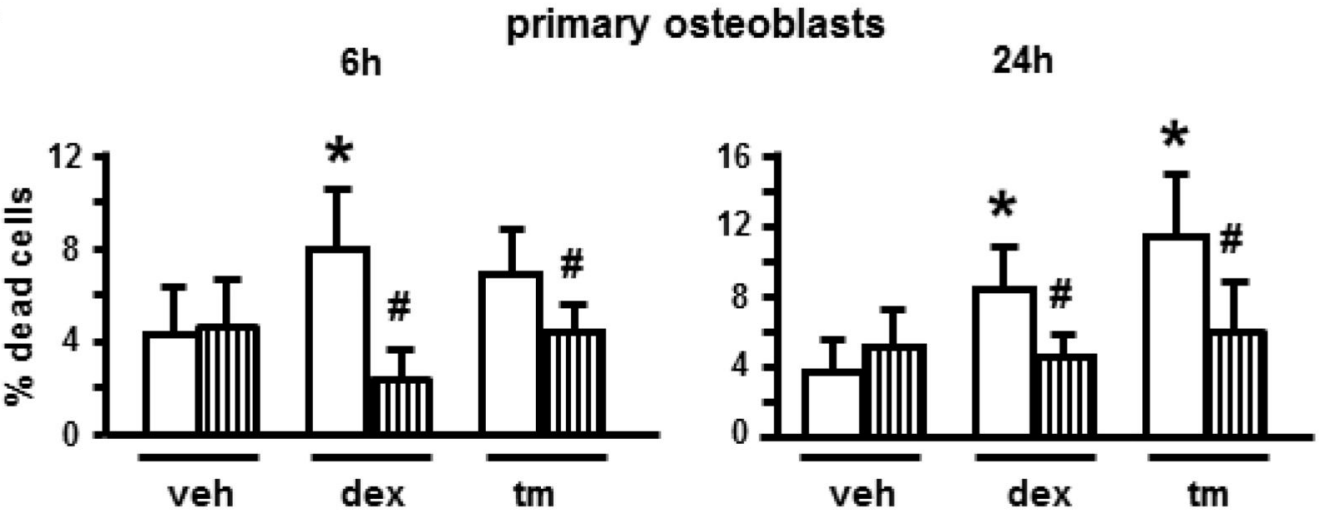

control

\section{IIIIIIII guanabenz}

Figure 3. Salubrinal or guanabenz protect from apoptosis induced by dexamethasone, etoposide, and ER stressors in osteoblastic cells

Cell death quantification in OB-6 osteoblastic (A and B) or primary osteoblastic $(\mathbf{C})$ cells treated with or without anti-apoptotic agents salubrinal, alendronate, or guanabenz prior to addition of dexamethasone (dex), etoposide (etop), brefeldin A (breA), tunicamycin (tm), or vehicle (veh). Bars represent the means \pm SD of $N=3$ samples per group. $* p<0.05$ vs. vehtreated cells and \# p $<0.05$ vs. corresponding apoptotic agent without designated eIF2a phosphatase inhibitor for each time point, by Student's t-test in (A) and (C) and by one-way ANOVA in (B). 


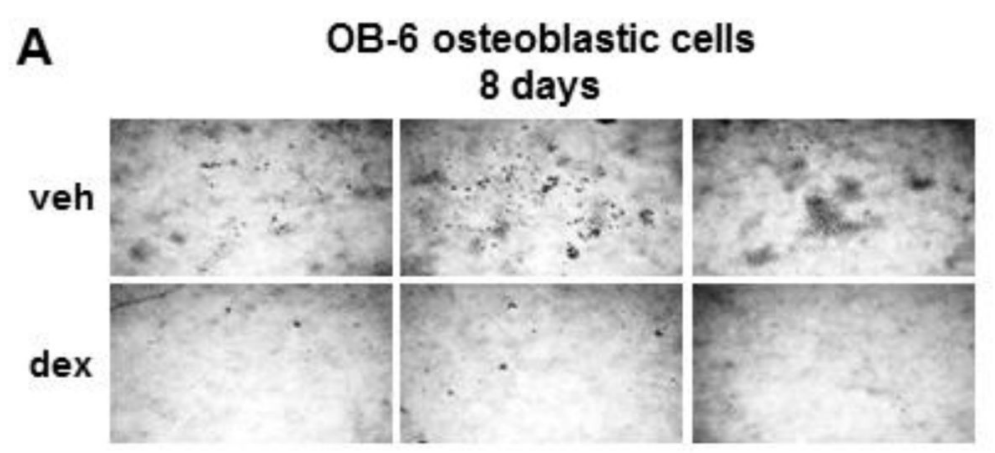

B

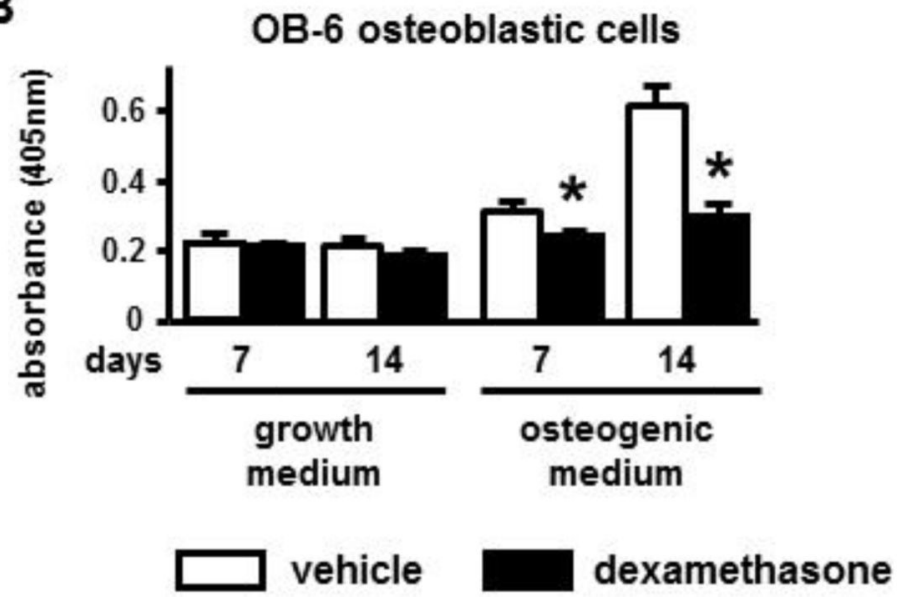

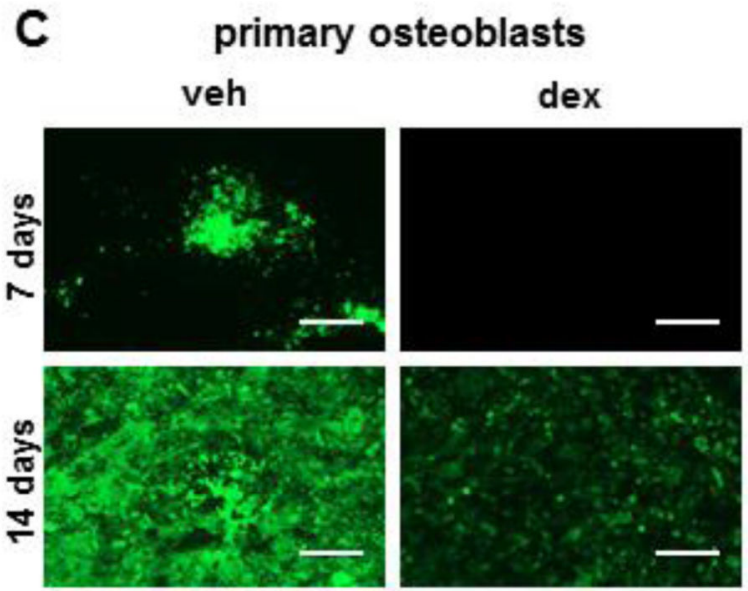

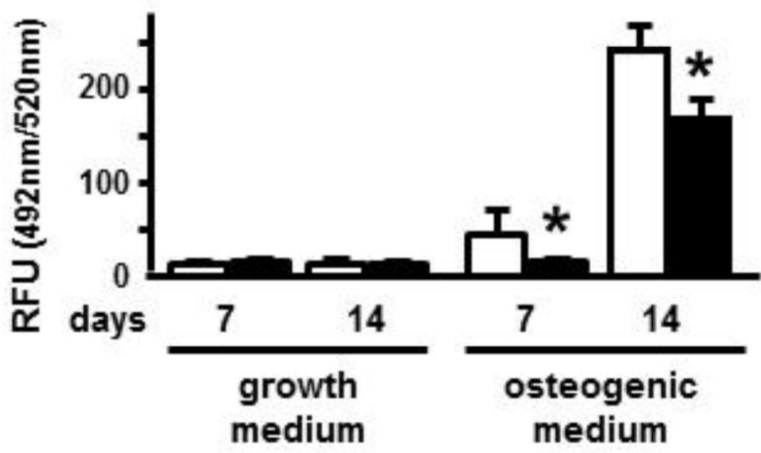

Figure 4. Glucocorticoid decreases matrix mineralization in cultures of osteoblastic cells and primary osteoblasts

(A and B) OB-6 osteoblastic cells cultured with or without dexamethasone (dex) and the degree of mineralization was assessed by von Kossa staining for 8 days (A) and by Alizarin Red S staining for 1 or 2 weeks (B). (C) Calvaria-derived osteoblastic cells were cultured with or without osteogenic medium for 1 or 2 weeks together with vehicle (veh) or dexamethasone (dex) and mineralization was assessed using the OsteoImage Mineralization Assay Kit. Lines correspond to $200 \mu \mathrm{m}$. Bars represent the means $\pm \mathrm{SD}$ of $\mathrm{N}=3$ for (A) and (B), N=6 for (C) samples per group. * $\mathrm{p}<0.05$ vs. veh-treated cells in corresponding medium condition for each time point, by two-way ANOVA. 

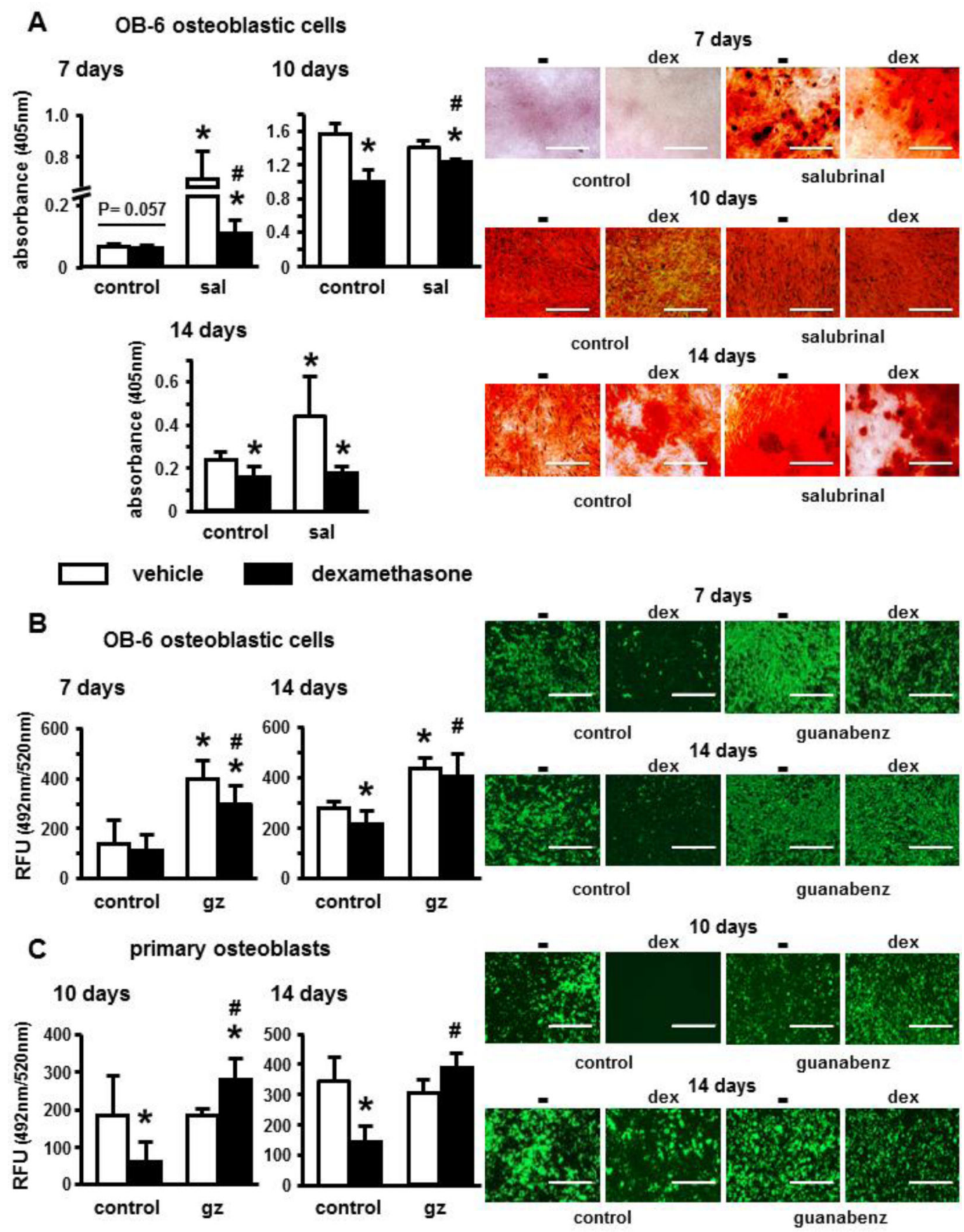

Figure 5. Salubrinal and guanabenz ameliorate the inhibitory effects of GC on matrix mineralization

(A) Mineralization was determined in vehicle (veh) or dexamethasone (dex) treated differentiated OB-6 cells without (control) or with salubrinal (sal) pre-treatment for 7, 10, and 14 days by Alizarin Red S staining. (B) and (C) Quantification of mineralization in OB-6 (B) and calvaria-derived (C) osteoblastic cells treated with vehicle or dexamethasone with or without guanabenz (gz) for the indicated incubation periods. Hydroxyapatite accumulation was measured by OsteoImage Mineralization Assay Kit. Lines correspond to 
$400 \mu \mathrm{m}$. Bars represent the means $\pm \mathrm{SD}$ of $\mathrm{N}=3$ for $(\mathbf{A})$ and $\mathrm{N}=12$ for $(\mathbf{B}-\mathbf{C}) . * \mathrm{p}<0.05$ vs. veh-treated control cells and \# $\mathrm{p}<0.05$ vs. dex-treated control cells, by one-way ANOVA. 
A apoptosis

cancellous osteoblasts

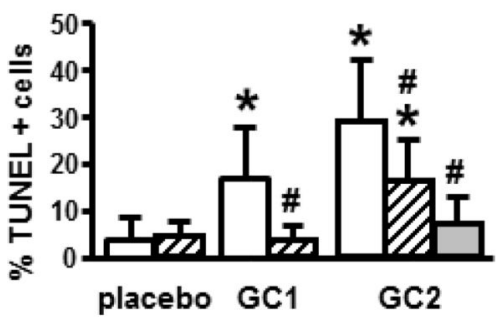

control $\mathbb{Z Z A}$ salubrinal

cancellous osteocytes

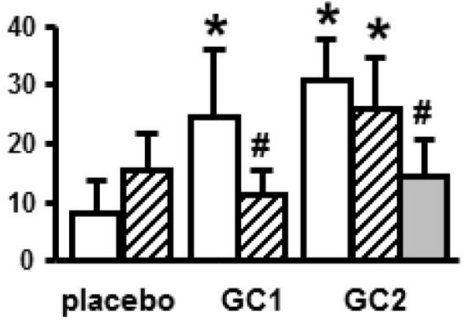

alendronate

B BMD
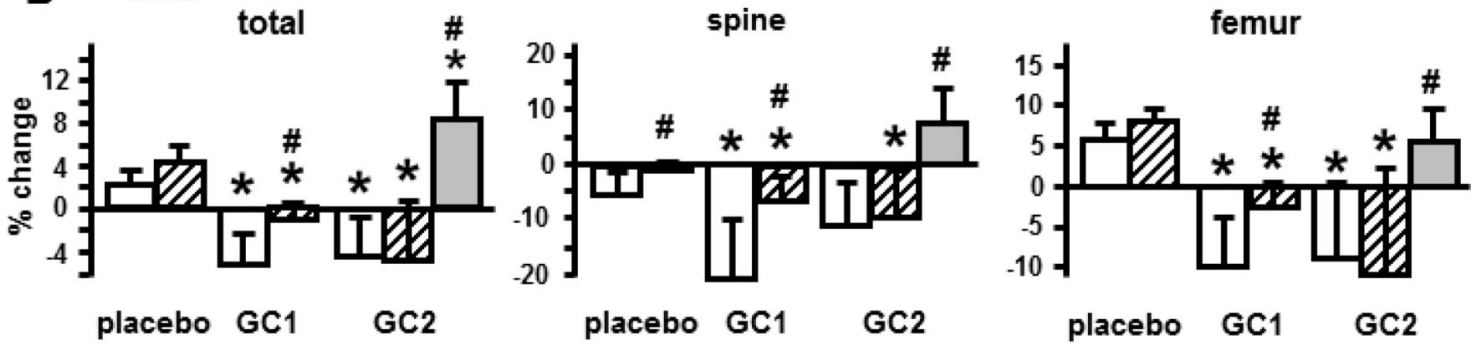

C bone formation

MS/BS

MAR
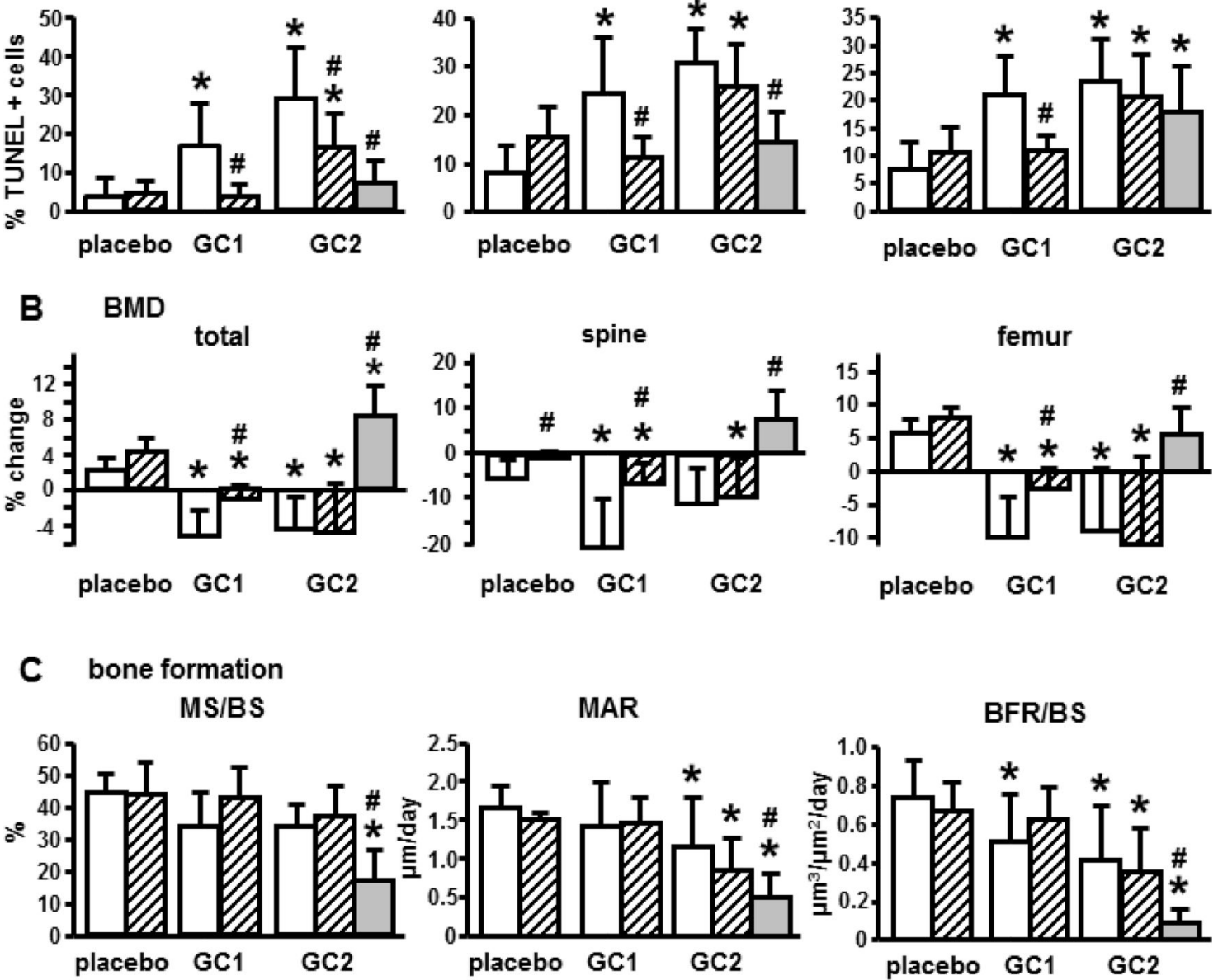

control

salubrinal

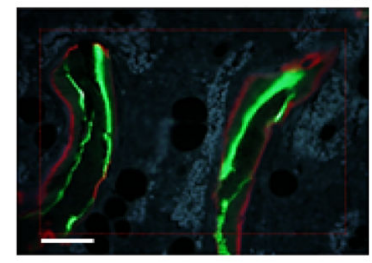

placebo

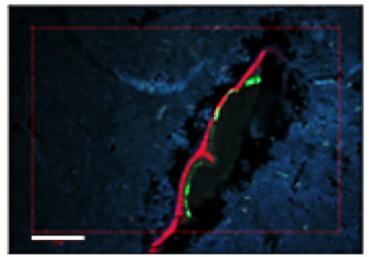

GC1

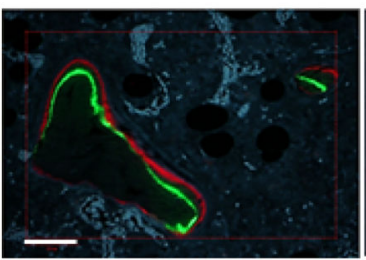

placebo

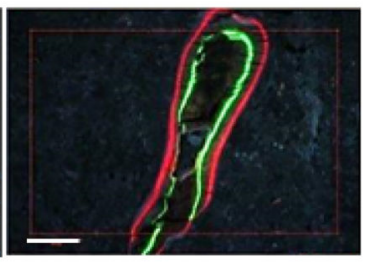

GC1

Figure 6. Salubrinal protects against glucocorticoid-induced apoptosis and consequent bone loss in vivo

(A) TUNEL and (C) dynamic histomorphometric data was obtained from longitudinal distal femur sections. Representative images of fluorochrome labeled bones are shown. Bars correspond to $50 \mu \mathrm{m}$. (B) BMD percent changes for placebo, $1.4 \mathrm{mg} / \mathrm{kg} / \mathrm{d}$ prednisolone (GC 1), or $2.1 \mathrm{mg} / \mathrm{kg} / \mathrm{d}$ prednisolone (GC 2) pellet implanted mice with or without salubrinal intervention were determined by DXA analysis. Bars represent the means $\pm \mathrm{SD}$ of $\mathrm{N}=7-10$ for (A) and (C) and N=6-10 for (B). Statistical analysis for placebo, GC1, and GC2 treated 
mice treated with vehicle (control) or salubrinal was performed by two-way ANOVA. *p < 0.05 vs. placebo mice injected with vehicle (control) or salubrinal. \#p $<0.05$ vs. the corresponding GC treated mice injected with vehicle (control). The effect of alendronate on $\mathrm{GC} 2$ treated mice was analyzed by comparing placebo, $\mathrm{GC} 2$, and $\mathrm{GC} 2$ plus alendronate by one-way ANOVA. *p $<0.05$ vs. placebo mice injected with vehicle (control) and \#p $<0.05$ vs. GC2 treated mice injected with vehicle (control). 